of that (Fortnightly Review, November 1894), I must content myself with trying to give you, in a few sentences, some idea of the range of his intellect.

His investigations on optics were not less important than those on sound. He invented the ophthalmoscope, by which the oculist can study the inmost recesses of the eye. The theory of colour vision, the theory of binocular vision, the curious subjective effects which are produced when we deliberately deceive our own senses by the stereoscope; these subjects he made especially his own.

In the field of mathematics he was the first to define the peculiar rotatory motion of a liquid known as vortex-motion. Great men had laid the foundations of hydrodynamics before him, but all had overlooked the importance and laws of the vortex. Since the memoir of Helmholtz was published the subject has been widely studied. Lord Kelvin has originated the famous vortex-ring theory of matter ; Prof. Fitzgerald has suggested that the ether may be a complex of vortices, or, as it has been called, a vortex-sponge.

On electricity he wrote much-on the theory of the galvanic cell, on electrolysis, on electromagnetism.

In England, at all events, we give the preference, as regards the last subject, to the theory and writings of our own Maxwell.

A lecture, or rather many lectures, might be delivered on each of these topics, but I prefer to devote the few minutes that remain to other subjects.

As I have already said, von Helmholtz, in an age of specialists, was a universal genius. His intellect could light on nothing which it did not illuminate. Hence his opinions on side issues are of more than ordinary importance, his "obiter dicta" are worth attention, his popular lectures acquire a special interest. Let us for a few moments turn to these.

The watchword of Helmholtz in dealing with educational problems is "freedom." Freedom for the student, freedom for the teacher.

In England we are fond of insisting that there are certain things which everybody who aspires to academic rank must know; of hedging in our students by prescribed courses of study. We make them feel that general culture is an ironbound safe, which they must wrench open before they can attain the gem of real knowledge, rather than a setting, without which the most profound acquirements seem unattractive and dull. Yet von Helmholtz, one of the most highly educated men, one of the most comprehensive geniuses of the latter end of the century, will have no set courses, except as a preparation for a definite profession, is proved that Germany has "retained the old conception of students, as that of young men responsible to themselves, striving after science of their own free will, to whom it is left to arrange their own plan of studies as they think best." Not content with having made the attainment of this ideal almost impossible for English students, doctrinaire educationalists are now beginning to throw their net around the teacher. It is claimed that as the student must go through a prescribed course of study in order to learn, so the teacher must be drilled and examined before he is allowed to teach. What. ever can be said for this plan as regards the less advanced class of teachers, who are to devote themselves to the instruction of children-and in this case I believe there is something to be said for it -it is quite opposed to von Helmholtz's view of what is best when the teaching is of university rank, and the students are men and women. Make it easy for whoever has given some proof of knowledge, and wants to teach, to try his hand ; make it easy for the student to go to the teacher from whom he gains the most. Look for the best educational results, not necessarily from the best lecturer, but from the man who is in closest con. tact with his subject. Do not force your teacher on his audience, but do all you can to establish a bond of sympathy between them. Trust, in a word, to the free play of living forces, and not to the hampering restrictions of "necessary subjects" and "compulsory lectures." This is a paraphrase of the views which Helmholtz held, and he illustrated them by the history of this Institution itself.

"I have often," he said, "wondered that the Royal Institution of London, a private society, which provides for its members and others short courses of lectures on the progress of natural science, should have been able to retain permanently the services of men of such scientific importance as Humphry Davy and Faraday. It was no question of great emolument; ; these men were manifestly attracted by a select public, con sisting of men and women of independent mental culture." And then he goes on to show that in a German university the teacher is attracted to his work, because he has to deal with a body of students, who are capable of forming opinions, and of judging what is best for themselves.

And this leads us to another point. Von Helmholtz insisted that it is useless and dangerous to crowd the universities with students, who are not capable of taking advantage of the opportunities they offer. "The majority of students," he says, "must come to us with a sufficiently logically trained judgment, with a sufficient habit of mental exertion, with a taste sufficiently developed on the best models to be able to discriminate truth from the bubbling appearance of truth. . . . It would be very dangerous for the universities if large numbers of students frequented them, who were less developed in [these] respects. The general self-respect of the students must not be allowed to sink. If that were the case, the dangers of academic freedom would choke its blessings. It must, therefore, not be looked upon as pedantry, or arrogance, if the universities are scrupulous in the admission of students of a different style of education. It would be still more dangerous if, for any extraneous reasons, teachers were introducet into the faculty, who have not the complete qualifications of an independent academical teacher." ("Popular Lectures," vol. ii. I 881, p. '264-5.)

It would be out of place on this occasion to attempt to apply these views to existing circumstances in London; but with the knowledge that the final constitution of a Teaching University for the metropoli; may be decided within the next few months, I cannot but feel that London will be happy if it escapes from the fetters which some of its so.called friends are forging for learning; and if, on the other hand, the wise determination of the Gresham Commissioners to include in the university only institutions of university rank, can be maintained against the attacks which will be made upon it.

Lastly, I wish to defend the memory of von Helmholtz from a possible misconception. Those who cultivate art may perhaps look upon him as the poet or the master of style look upon the grammarian, as a mere gerund-grinder, occupied with the study of the dead materials which they alone can use. Of course Helmholtz was not a great artist in the sense that he was a great scientific man, but it would be most unfair to picture him as interested only in the study of laws, and as insensitive to beauty, as occupied with sound and light, but careless as to music and painting. I could quote passage after passage from his works to prove his keen sense of the loveliness as well as of the order of nature, to show the homage that he paid, and the freedom he accorded to art. His object was not to lead art captive to science; but rather to unite them in an alliance of mutual confidence and support.

"The horizons of physics, philozophy, and art have," he said, " been too widely separated, and, as a consequence, the language, the methods, and the aim: of any one of these studies presents a certain amount of difficulty for the student of any other of them." To smooth away these difficulties, to bridge over the separating gulf, to supply the common language, were the objects of the life-work of von Helmholtz. It was a noble ideal, nobly pursued, and crowned with as much success as could reward the efforts of one man. It is an ideal akin to that which dominates this Institution, where science, literature, and art are all heard in turns.

If it is possible to sum up in a sentence the teaching of von Helmholtz, and the work of hi; life, it is that, in spite of the apparent diversities between science and science, between science, philosophy, and art, there is a fundamental unity, and that the future is for those who detect, amid the seeming discords of the schools, the true harmony which underlies and dominates them all.

\section{ELECTRIFICATION OF AIR AND OTHER} GASES.

$\S$ I. $\mathrm{A} T$ the meeting of the British Association in Oxford in August 1894 , a communication was given to Section A, entitled "Preliminary Experiments to find if Subtraction of Water from Air Electrifies it." These experiments were performed during July of 1894 , and were a continuation of experiments which were commenced in the Physical Laboratory of the University of Glasgow in December of 1868 with the same object, but which were then, for various reasons, discontinued before any decisive result had been obtained.

1 A Paper by Lord Kelvin, P.R.S., Magnus Maclean, and Alexander Galt, read at the Royal Society on February $2 \mathrm{r}$. 
\& 2. A glass U-tube with vertical branches (Fig. I), each I8 inches long and about $\mathrm{I}$-inch bore, with the upper 8 inches of one of the branches carefully coated outside and inside with clean shellac varnish, was held fixed by an uninsulated support attached to the upper end of this branch. The other branch was filled with little fragments of pumice soaked in strong sulphuric acid or in water, and a fine platinum wire, with one end touching the pumice, connected it to the insulated electrode of a quadrant electrometer. A metal can, M, large enough to surround both branches of the U-tube without touching either, was placed so as to guard the tube from electric influences of surrounding bodies, the most disturbing of which is liable to be the woollen cloth sleeves of the experimenters or observers moving in the neighbourhood. This metal can was kept in metallic connection with the outside metal case of the

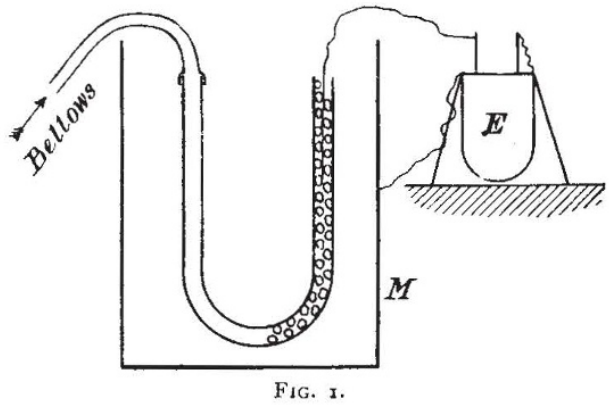

quadrant electrometer. The length of the exposed platinum wire between the $U$-tube and the electrometer was so short that it did not need a metal screen to guard it against irregular in. fluences. An india.rubber tube from an ordinary blow-pipe bellows was connected to the uninsulated end of the U-tube. Air was blown through it steadily for nearly an hour. With the pumice soaked in strong sulphuric acid in the other branch, the electrometer reading rose in the course of three-quarters of an hour to about 9 volts positive. When the pumice was moisttened with water, instead of sulphuric acid, no such effect was observed. The result of the first experiment proves decisively that the passage of the air through the $U$-tube gave positive electricity to the sulphuric acid, and therefore sent away the dried air with negative electricity. A corresponding experiment with fragments of pure chloride of calcium instead of pumice in sulphuric acid, gave a similar result. In repetition calcium in lumps, not specially dried, gave no effect in the straight tube; but if previously heated to $180^{\circ}$ or $200^{\circ}$ and put in to the straight tube when still hot, it gave an enormous positive electrification immediately on the commencement of blowing. Strong positive electrification was obtained a second time, by discharging the electrometer to zero, re-insulating, and recommencing the blowing. But after discharging a second time, re-insulating, and re-commencing the blowing, no further electrification was found.

$\S 4$. In continuation of these experiments on September 25, the arrangement represented in Fig. 2 was set up. The outer metallic guard-vessel, $\mathrm{M}$, was kept connected by a wire to the case, and to one pair of quadrants of a quadrant electrometer, $\mathrm{E}$. The water in the inner glass jar, A, was connected by a pla. tinum wire to the other pair of quadrants of the electrometer.

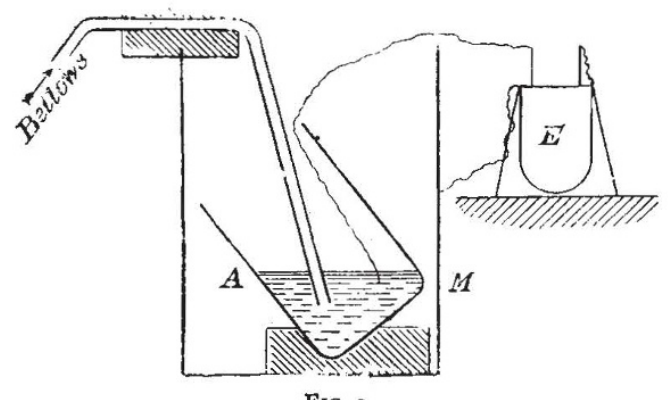

Fig. 3.

To have this inner jar well insulated, it was supported on a block of paraffin; and the other end of the glass tube dipping into the water was fitted into one end of a tube of paraffin, to the other end of which was fitted a tube for ingress of air, from bellows, as shown in the figure. The insulation of this arrangement was found to be good. When air was blown through the water it was found that the jar containing the water became positively electrified.

§ 5. To prevent splashing of water out of the jar, a paper cover was put on its mouth, or the jar was tilted, as shown in Fig. 3, so that the bubbles broke against the inside of the jar. In three experiments thus made, the same electrification was still found, amounting to about 6 volts positive in a quarter of an hour.

$\S 6$. As the jar was in every experiment positively electrified,

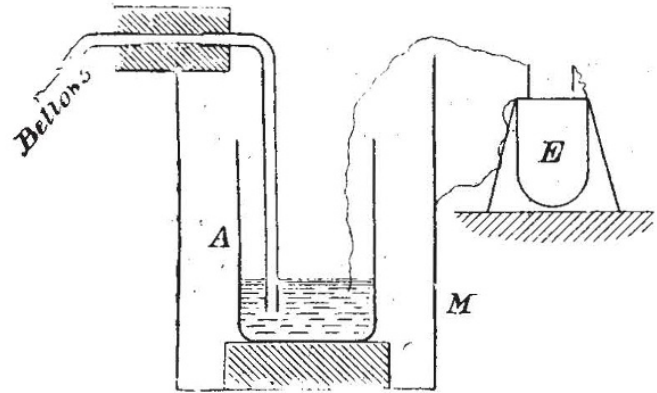

FIG. 2.

of the experiments, however, it was noticed that the strong positive electrification of the U-tube seemed to commence somewhat suddenly when a gurgling sound-due to the bubbling of air through free liquid, whether sulphuric acid or chloride of calcium solution in the bend of the U-tube--began to be heard. It has since been ascertained that it was because no liquid accumulated in the bottom of the U-tube that no electric effect was found when the pumice was moistened with pure water.

\& 3. Arrangements were made to prevent any bubbling of the air through liquid, by using a straight tube instead of a U.tube. In a large number of experiments with pumice, moistened with pure sulphuric acid in the straight tube, and air blown through for about half an hour, no definite electrification was obtained. In this straight tube, as formerly with the U-tube, pumice moistened with pure water gave no electrification. Chloride of

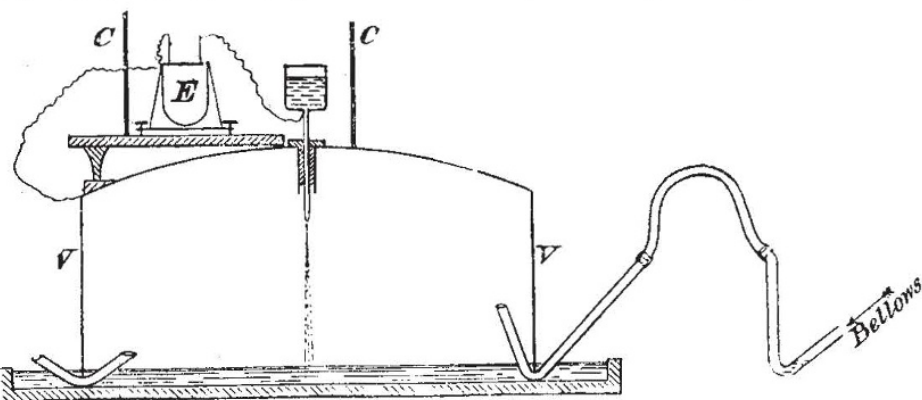

FIG. 4.

the air, if unelectrified ${ }^{1}$ when entering it, must have been negatively electrified when leaving it.

\$ 7 . To test if the air was negatively electrified after bubbling, on October II the apparatus ${ }^{2}$ shown in Fig. 4 was set up. The apparatus consists of a large sheet iron vat, $\mathrm{v} v$, $123 \mathrm{~cm}$. in diameter and $70 \mathrm{~cm}$. in height, inverted on a large wooden tray lined with lead, and supported by three blocks of wood. By filling the tray with water the air is confined in the vat.

C $\mathrm{C}$ is a metal screen kept metallically connected with the

1 Air was similarly blown from bellows into the vat (see § 7) without any bubbling, and no electrification was observed.

2 The vat, the water-dropper, and the electrometer are the same as in the apparatus described in the Proceedings of the Royal Society, vol. 56, year 1894, "Electrification of Air," by Lord Kelvin and Magnus Maclean.

NO. I 325 , VOL. $5 \mathrm{I}]$ 
case of the electrometer, and with the vat. It surrounds both the electrometer and the water-dropper, to prevent any external

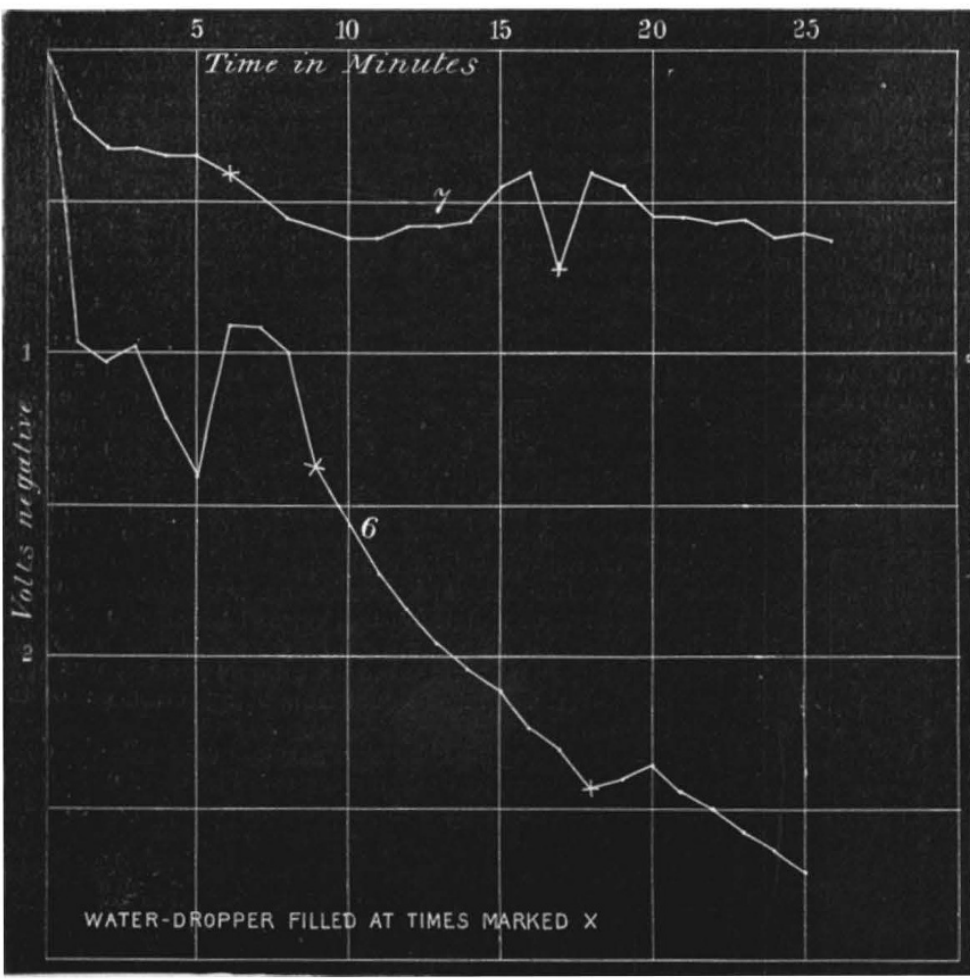

varying electrifications from vitiating the proper results of our experiments.

This screening of the electrometer is absolutely necessary when it is used with high sensibility (7o scale divisions per volt in our experiments) in a laboratory or other place where various other electric experiments may simultaneously be going on. Four years ago the electrometer, the vat, and the water-dropper, were set up on the class-room table without a metal screen. When the deflection indicated about 4 volts negative (see $\$ 8$ ), the negative lead of Lord Kelvin's house electric-light circuit, which passes through the class-room, was joined to earth. This changed the deflection of the electrometer suddenly by $\mathrm{I}$ volt in the positive direction. When the positive lead was " earthed," the deflection was changed suddenly by 6 volts in the negative direction. Putting on sixteen 8 c.p. electric lamps, eight on each side of the class-room, changed the deflection by two-thirds of a volt in the negative direction.

\& 8. In experimenting with the same apparatus ${ }^{1}$ in 1890 , it 1 Phil. Mag. August, 1890 , "Electrification of Air by a Water Jet," by Maclean and Goto.
CuRves 6 AND 7.

I

(1)

$\stackrel{.}{.}$

究

$\mathbf{I}$

$\frac{n}{0}$

2

3

4

5

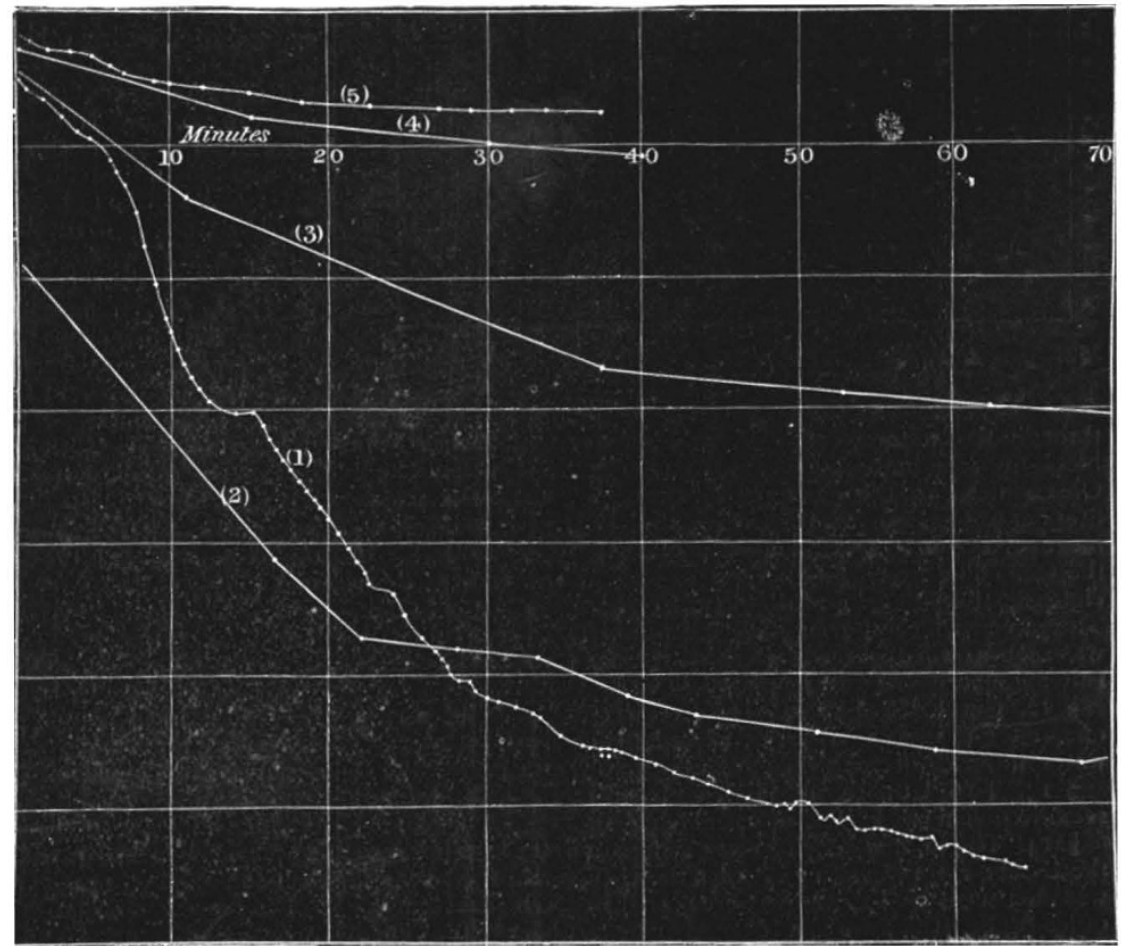

CuRves I to 5

6 laboratory enclosed in the vat. The present experiments fully confirm this result, showing a gradual negative electrification of the enclosed mass of air rising to about 5 volts in an hour, once every day for the first few days. For twentyeight days after the vat was set up, in October r894, fifteen observations of an hour each were taken to find the effect of the water-dropper, with no other disturbing influence on the unchanged volume of air inside the vat. These experiments verify the conclusion (Phil. Mag., August 1890) that the more the air inside the vat became free of dust, the less became the rate at which the air was negatively electrified by the water-dropper.

$\S 9$. On October 15 last the vat was lifted from the tray to remove some obstruction in the nozzle of the water-dropper, which was not then flowing freely. Curve (6) was obtained that afternoon. The air in the vat was the ordinary air of the laboratory, and the curve shows the effect of the water-dropper alone in electrifying the air negatively. For the next two days the water-dropper was kept running continuously for about eight hours each day, to wash the dust out of the air, and on October I 8 curve (7) was obtained. It shows a much less rate of negative electrification than curve (6). In the experiments of summer I 890 an aspirator was used to draw the air from the vat, and a tube full of cotton-wool was used to filter the air drawn into the vat.

Curves (I) to (5) are reproduced from the Philosophical Magazine, and they show that the more the air becomes free from dust the less is the rate at which the

No. I 325 , vOL. $5 \mathrm{I}]$ 
water-dropper electrifies. Thus curve (I) was obtained from the ordinary air of the laboralory in the vat, and curve (2) after the aspirator was working for some time. In this curve the water-dropper itself was running for some time before the first observation was taken. The other curves were obtained after further continuous working of the aspirator.

After curve (4) was obtained the aspirator was worked continuously for twenty-five hours, and then curve (5) was obtained.

$\S$ ro. At the end of twenty-three days of October and November 1894 ( $\$ \& 8,9$, above), when the air inside the vat must have been fairly free from dust, and when the water-dropper of itself was giving little negative electrification, we bubbled air into it by a forked tube, one end of which was connected to a bellows, and three other open ends were below the water inside the vat. In five experiments thus made-two on November 7 , two on November 8 , and one on December 17 , an average negative electrification of 5 volts in twelve minutes was obtained.

\& II. We now arranged a U-tube with pure water in it (Fig. 4) outside the vat. Air from the bellows bubbled

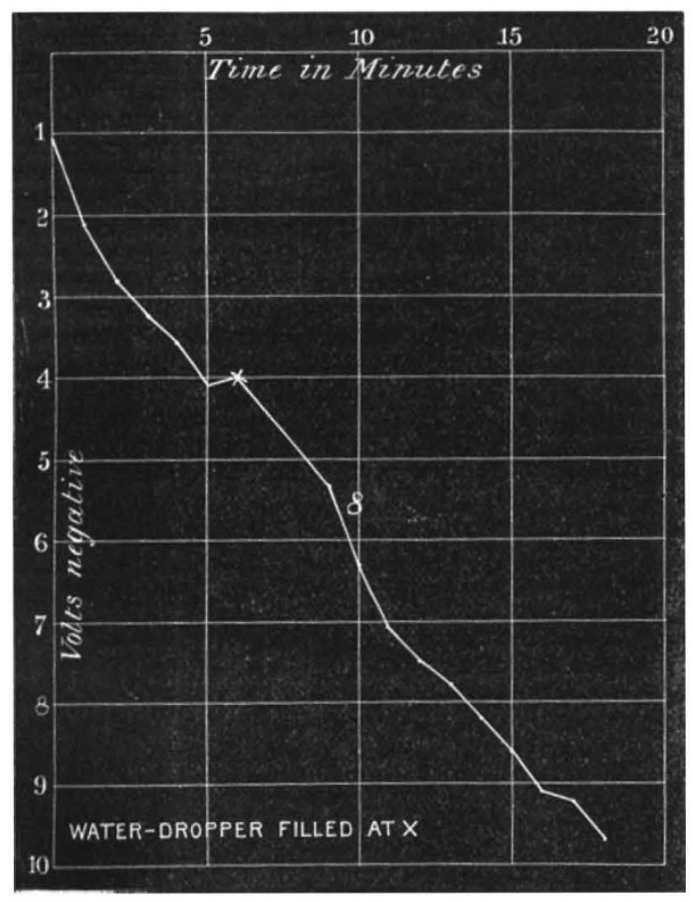

Curve 8.

through the water in this $U$, and was carried thence by a block-tin pipe into the vat without any further bubbling. Observations by the quadrant electrometer, while the waterdropper was running and the bellows worked, gave us measurements of the varying state of the electrification of the air in the vat. The average of fifteen experiments gave a negative electrification of the air in the vat of $8 \frac{1}{2}$ volts in 25 minutes. The rate at which the air was blown in in these experiments was such as to displace the entire volume of air in the vat in half an hour.

$\S$ 12. Curve (8) shows the rate of electrification of air, in one of the fifteen experiments, when thus bubbled through the water in the $U$-tube and then admitted into the vat.

$\S$ I3. Two U-tubes, in series, with water in each, did not seem to give a perceptibly cumulative effect.

$\S 14$. The effect of one or more wire gauze strainers between the $U$-tube and the vat, or between the U-tube and the bellows, was next tested. The gauzes were placed between short lengths of lead tube, which were held together by a rubber tube slipped over them. The arrangement is shown by longitudinal and cross sections in Fig. 5. Twelve wire gauzes, with or without No. 1325 , vor. 51$]$ cotton-wool between them, placed between the bellows and the U-tube, did not prevent the subsequent electrification by bubbling of the air thus filtered. But when placed between the $U$-tube and the vat they almost entirely diselectrified the air, even without the cotton-wool, and still more decidedly when cottonwool was loosely packed between the wire gauzes. A single wire-gauze strainer produced but little of dis-electrifying effect.

\$15. The interpretation of these experiments is complicated, and the time required for each is lengthened, on account of the large mass of air in the vat to start with, whether uncharged or retaining electricity from previous experiments, and also on account of the effect of the water-dropper itself. Hence, in our later experiments, we fell back on the arrangement shown in Fig. 2, by which we test the electrification of the liquid, and not directly that of the gas blown through it.

§ 16. In our first experiment with this apparatus the amount of the electrification did not seem much affected when a paper cover was put on the beaker, or when we tilted the beaker as shown in Fig. 3. We now made a large number of tests with different covers and screens (chiefly of sheet copper or sheet zinc, or brass wire gauze) at different heights above the liquids, and we concluded that, if the screens are not within a centimetre and a half of the liquid surface, they do not directly affect the magnitude of the electrifica. tion obtained. In nearly all of the subsequent experiments a horizontal circular screen of thin sheet copper, leaving an air space of about $3 \mathrm{~mm}$. all round between its edge and the inner surface of the jar, about $3 \mathrm{~cm}$. above the liquid surface, was used to prevent spherules of the liquid from being tossed out of the jar by the bubbling.

$\$ 17$. In the following short summary of our results the duration of each experiment was ten minutes. The effect of blowing air through water and other liquids is summarised in $\$ \S 18$ to
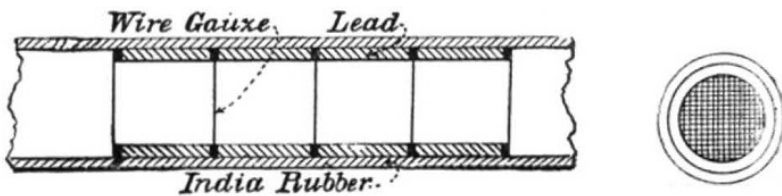

FIG. 5.

27 , and of blowing other gases than air through water in $\$ \S 28$ to $3 \mathrm{I}$.

\$ I8. The jar contained 200 c.c. of the Glasgow town-supply water (from Loch Katrine). A mean of seventeen experiments showed an electrification of the jar to four volts positive when air was blown through it for ten minutes.

$\S$ 19. A solution of zinc sulphate of different strengths was now used instead of the pure water. Three experiments, with $15^{\circ}$ c.c. of water containing one drop of a saturated solution of the zinc sulphate, gave half the positive electrification that would, under similar circumstances, have been obtained from wate only. With five drops no definite electrification was obtained. $W$ ith greater proportions of the zinc sulphate solution up to saturation (twenty-four experiments altogether) the electrification was on the average slightly negative.

$\$ 20$. Twelve experiments were then made to test the effect of adding a solution of ammonia to the water. One drop reduced the electrification to one-half; two drops brought it down to one-quarter. With larger proportions of ammonia than this, up to a saturated solution, we found a very slight positive electrification, never amounting to more than a small fraction of a volt, and therefore negligible in the circumstances.

$\$ 21$. Seven experiments with sulphuric acid of different strengths all showed small positive electrification, the amount gradually decreasing from $\frac{1}{4}$ volt, in ten minutes, with $0^{\circ} 5$ per cent. acid in water to $\frac{7}{16}$ volt, in the same time, with acid of full strength.

Seven experiments with hydrochloric acid solution of different strengths all showed a small negative electrification, the amoun gradually increasing from $\frac{1}{2}$ volt, in ten minutes, with $\frac{1}{3}$ per cent. acid solution in water to $1 \frac{1}{4}$ volts, in the same time, with acid solution of full strength.

Nine experiments with calcium chloride solution were made. A saturated solution and a solution diluted to 75 per cent. of full strength gave no result; but solutions of gradually diminished strength, from 50 per cent. down to $\frac{1}{10}$ per cent., 
showed a negative electrification from fully $\frac{1}{2}$ volt, in ten minutes, down to volt.

Additions of very small quantities of washing soda to water greatly reduce the positive electrification obtained.

Loch Katrine water, supersaturated with carbonic acid, and placed in the insulated jar, showed, when air was bubbled through it for ten minutes, a negative electrification of $\frac{1}{4}$ volt.

$\S 22$. Ten drops of paraffin oil added to water reduced the electrification to about half of that obtained from water only. Thirty drops reduced it to about a tenth, which, as it amounted to only 0.4 volt during the time of the experiment is negligible.

\$23. Ten drops of benzene reduced the electrification to half, and thirty drops to about a third of that taken by pure water.

$\S 24$. A saturated solution of granulated phenol (carbolic acid) was made, and small portions of it added to the water in the jar. Several experiments showed no diminution in the electrification as long as the quantity of the phenol solution present in the water was under Io per cent. With 25 per cent. the electrification was reduced to a third. With strengths greater than this up to saturation the electrification was reduced to one-sixth.

$\$ 25$. A saturated solution of common salt was prepared. Blowing air through 200 c.c. of water containing the quantities of the salt solution mentioned, gave us in ten minutes the following electrifications :-

\begin{tabular}{|c|c|c|c|c|}
\hline $\begin{array}{l}\text { Per cent. of } \\
\text { aturated solution of } \\
\text { salt in water. }\end{array}$ & & & & $\begin{array}{c}\text { Volts } \\
\text { positive }\end{array}$ \\
\hline (a) 0.004 & $\cdots$ & $\cdots$ & $\ldots$ & $2 \cdot 4$ \\
\hline (b) 0.02 & $\ldots$ & $\ldots$ & $\ldots$ & $1 \cdot 2$ \\
\hline (c) $O \cdot I$ & $\ldots$ & $\ldots$ & $\ldots$ & 0.6 \\
\hline (d) 0.5 & $\ldots$ & $\ldots$ & $\cdots$ & 0.4 \\
\hline (c) $2 \%$ & $\ldots$ & $\ldots$ & $\ldots$ & 0.15 \\
\hline (f) $4^{\circ} \mathrm{O}$ & $\ldots$ & $\ldots$ & $\ldots$ & 0.0 \\
\hline
\end{tabular}

$\S 26$. Several experiments showed that with 200 c.c. of water containing not more than ten drops of absolute alcohol practically the same amount of positive electrification (4 volts in ten minutes) is obtained as if pure water were used. With filty drops less than 2 volts were got, and with roo drops less than $I$ volt. 25 and 50 per cent. alcohol in the water gave very small and hence negligible positive electrification.

$\$ 27$. One drop of saturated solution of copper sulphate in 200 c.c. of water showed one volt positive in ten minutes. With $\frac{1}{2}$ per cent. of it in the water, the electrification was reduced to a fraction of a volt positive. With greater proportions of copper sulphate present, up to saturation, slightly negative electrifications were obtained, but never amounting to more than about one-tenth of a volt, and hence negligible.

$\S 28$. On blowing carbonic acid gas from a cylinder obtained from the Scotch and Irish Oxygen Company, through pure water in the glass jar, the water became electrified to $8 \frac{3}{4}$ volts positive in ten minutes. Blowing the breath through water gave an electrification of 3 volts positive in the same time: this diminished result is doubtless due chiefly to the diminished rate of bubbling.

$\S 29$. The blowing of oxygen from a cylinder, obtained from the Oxygen Company, through water, gave as a mean of four experiments a positive electrification to the water of half a volt in ten minutes. When continued for fifty-five minutes, it gave the very decided result of 5 volts positive.

$\$ 30$. Hydrogen prepared from zinc and dilute sulphuric acid was passed into a large metal gas-holder; and was passed on from this to bubble through the water in the insulated jar. In two experiments this was done immediately after the preparation of the hydrogen; in another it was done after the hydrogen had remained eighteen hours in the gas-holder. In each of the three experiments the water was electrified to 2 volts positive in ten minutes.

When the hydrogen was allowed to pass direct through a tube from the Wolffe's bottle where it was generated, to bubble in the insulated jar, the magnitude of the effect obtained was very much larger. In one case a mixture of muriatic acid and sulphuric acid and water was used, and the reading went off the scale positive in thirty seconds (more than Io volts). In other two experiments with dilute sulphuric acid and zinc in the Wolffe's bottle, the electrifications obtained were 6 volts positive in seven minutes, and $7 \cdot 3$ volts positive in thirteen minutes, in the last of which the hydrogen was allowed to bubble through caustic potash contained in a small bottle between the Wolffe's bottle and the insulated jar.

The bydrogen was next generated in the insulated jar itself, the tube for ingress of air used in the ordinary experiments being taken away. 200 c.c. of pure water, along with some granulated zinc, was put into the jar. Then some pure sulphuric acid was added, and electrometer readings were taken. In two experiments with no screen in the jar (\$ I 6 ) the reading went off the scale negative (r) in two minutes and (2) in four minutes (more than 9 volts in each case). In another experiment in other respects the same, but with a copper screen $7 \mathrm{~cm}$. above the surface of the liquid, the electrification showed 2 volts negative in two minutes, then came back to zero in five minutes, and in the next six minutes went 4 volts positive. The jar and pair of quadrants connected with it were then metallically connected with the outer case of the electrometer for a few seconds, and reinsulated ; in five minutes the reading went up to 2 volts positive. A little more sulphuric acid was added to the jar, which was disinsulated for a short time and reinsulated; the reading went up to 7 volts positive in four minutes. The jar was again disinsulated for a few seconds and reinsulated ; the reading went up in four and a half minutes to $6 \frac{1}{3}$ volts positive.

$\S 3$ I. Coal-gas, bubbled through water in the insulated jar, gave $I$. 4 volts positive in ten minutes.

$\$ 32$. In the ordinary experiment of hubbling air through a small quantity of water in the bottom of the jar it was noticed that the electrification did not commence to be perceptible generally till about the end of the first minute ; and that it went on angmenting perceptibly for a minute or more after the bubbling was stopped. The following experiment was therefore tried several times. One of us stood leaning over the jar, with the head about Io inches above it, and the mouth so partly closed that breathing was effected sideways; another blew the bellow; and another took the readings of the electrometer. After bubbling had been going on for some minutes, and the readings were rising gradually (4 volts per ten minutes, as in $\S 18$ ), blowing was stopped. As soon as the bubbling ceased, the first-mentioned observer, without moving his head or his body (see $\$ 7$, regarding the necessity to have the electrometer screened from outside influences), blew into the jar to displace the negatively electrified air in it. In every case the electrometer reading showed instantiy a small rise in the positive direction.

In the carrying out of these experiments we have received much valuable help from Mr. Walter Stewart and Mr. Patrick Hamilton.

§33. The very interesting experiments describet hy Lenard, in his paper on the Electricity of Waterfalls (Wiedemann's Annalen, 1892, vol. 46, pp. 584-636). ant by Prof. J. J. Thomson, on the Electricity of Drops (Phil. Mag. April I894, vol. 37, pp. 34I-358), show phenomena depending, no doubt, on the properties of matter, to which we must look for explanation of the electrical effects of bubbling described in our present communication, and of the electrification of air by drops of water falling through it, to which we have referred as having been found in previous experiments which were commenced in 1890 for the investigation of the passage of electrified air through tubes. ${ }^{1}$

\section{UNIVERSITY AND EDUCATIONAL INTEELIGENCE.}

CAmbridge. - The Isaac Newton Studentship in Astronomy has been awarded to Mr. S. S. Hough, Scholar of St. John's College, Third Wrangler in 1892 , and Smith's Prizeman in 1894 .

Mr. C. T เ Heycock, Lecturer in Chemistry at King's College, First Class in the Natural Sciences Tripos 1889 has been elected to a Fellowship.

The discussion by the Senate of the proposals for the encouragement of Advanced Study and Research, by the admission under special conditions of Graduates of other Universities, was on the whole favourable to the scheme. There seems litıle doubt that the preliminary resolutions on the subject will be passed early next term.

Mr. Arthur R. Hinks, of Trinity College, has been appointed Second Assistant at the Observatory for five years, from July I, 1895 .

1 "Electrification of Air by a Water Jet." By Magnus Maclean and Makita Goto, Phil Mag. August I89o, vol. 30, Ip. I48-152.

NO. I 325 , VOL. $5 \mathrm{I} 7$ 